\title{
PEREMPUAN DALAM JERAT TERORISME: ANALISIS MOTIVASI PELAKU BOM BUNUH DIRI DI INDONESIA
}

\begin{abstract}
:
Recent acts of terrorism have experienced a shift in perpetrators. If all this time women were only behind the scenes, now they have started to show themselves as main actors such as weapons providers, bomb builders and even suicide bombers. The women involved as perpetrators are actually victims of the snares of terrorism. This paper aims to analyze what are the motivations behind women who are entangled in the vortex of terrorism so that they are willing to become suicide bombers. The results of the study found at least six factors that caused women to be willing to become combatants, namely the occurrence of jihad indoctrination deviations, the lure of going to heaven, married by terrorist, discriminated feeling, frustrated feeling so that suicide bombing is a shortcut to repentance and revenge for being victims of sexual harassment.
\end{abstract}

Key word: women, terrorism, suicide bombing

\begin{abstract}
Abstrak:
Aksi terorisme belakangan ini mengalami pergeseran pelaku. Jika selama ini perempuan hanya ada di balik layar, kini mereka sudah mulai menunjukkan diri sebagai pemeran utama seperti penyedia senjata, perakit bom bahkan menjadi pelaku lapangan bom bunuh diri. Para perempuan yang terlibat sebagai pelaku sesungguhnya adalah korban dari jerat terorisme. Tulisan ini bertujuan untuk menganalisis motivasi apa saja yang melatarbelakangi perempuan yang terjerat dalam pusaran terorisme sehingga bersedia menjadi pelaku bom bunuh diri. Hasil penelitian menemukan setidaknya enam faktor yang menyebabkan para perempuan bersedia menjadi kombatan yakni terjadinya penyimpangan indoktrinasi jihad, iming-iming masuk surga, bersuamikan seorang teroris, adanya perasaan terdiskriminasi, rasa frustasi sehingga menganggap bom bunuh diri adalah jalan pintas pertobatan dan upaya balas dendam karena menjadi korban pelecehan seksual.
\end{abstract}

Kata kunci: perempuan, terorisme, bom bunuh diri

\section{PENDAHULUAN}

Aksi terorisme kembali mengejutkan publik tanah air. Setelah serangan bom bunuh diri di Gereja Katedral Makasar pada Minggu, 28 Maret 2021. Mereka meledakkan diri di gerbang Gereja Katedral Makasar, di saat umat Katolik sedang melakukan ibadah misa dalam rangkaian pekan suci menuju Paskah. Pelakunya adalah sepasang suami istri. Tidak lama berselang, pada Rabu, 31 Maret 2021 aksi teror di Mabes Polri yang berujung pada tewasnya pelaku kembali 
terjadi. Pelakunya juga seorang perempuan. ${ }^{1}$ Beberapa tahun belakangan kita bisa membuka catatan adanya sosok Dian Yulia Novi yang akan meledakkan Mabes Polri pada 11 Desember 2016 atau lebih popular dengan nama bom panci yang berhasil digagalkan Tim Densus 88 . Setelah Dian, muncul nama Ika Puspita Sari di Purworejo yang akan melancarkan aksi bom bunuh diri di luar Jawa. Lalu, Umi Delima, isteri teroris Santoso di Poso. Penangkapan ketiga orang tersebut menambah jumlah nama perempuan dalam pusaran terorisme. Di antara beberapa nama yang tertangkap sebelumnya, yaitu Putri Munawwaroh, Inggrid Wahyu, Munfiatun, Rasidah binti Subari, Ruqayah binti Husen Lecano, Deni Carmelit, Rosmawati, dan Arina Rahma. ${ }^{2}$ Tak berhenti di sana , aksi serupa kemudian menyusul di Surabaya dan Sidoarjo pada 13 dan 14 Mei 2018 juga melibatkan perempuan. Tiga bom pertama yang meledak di tiga gereja di Surabaya dilakukan satu keluarga. Dita Oeprianto mengajak istrinya, Puji Kuswati, dan empat anaknya. Peristiwa ini menewaskan enam pelaku dan 12 orang lainnya. Keesokan harinya Tri Murtono bersama istrinya, Tri Ernawati, dan ketiga anaknya, meledakkan diri di pintu gerbang Mapolresta. Pasangan suami-istri tersebut dan dua anaknya tewas, sedangkan satu anak mereka yang lain terluka. ${ }^{3}$

Maraknya teror di Indonesia yang melibatkan peran perempuan aktif semakin banyak terjadi dan semakin subur, sedikit banyak dipengaruhi adanya peran perempuan yang tampak semakin aktif dalam pola aksi terorisme baik secara global maupun regional. Stereotip perempuan sebagai seseorang yang memiliki karakter keibuan penuh kasih, dan anak-anak yang terlihat tidak berbahaya bahkan rapuh seringkali mengecohkan dan luput dari intaian dan kecurigaan petugas keamanan setempat. Impian dan janji masa depan yang lebih baik untuk keluarga menjadi alasan yang menggerakkan mereka. Ideologi semacam itu kemudian menjadi pembenaran untuk melakukan aksi bom bunuh diri bersama anggota keluarga (family bombing). ${ }^{4}$

Fakta-fakta yang kita lihat di atas, menunjukkan bahwa telah terjadi pergeseran peran yang signifikan dari para perempuan dalam aksi terorisme. Jika selama ini para perempuan hanya ada di balik layar dan ranah domestik seperti fasilitator operasional, penyuplai logistik

${ }^{1}$ Fahreza Rizky, "Fakta-Fakta Serangan Di Mabes Polri Dan Bom Bunuh Diri Makassar," April 1, 2021, https://nasional.sindonews.com/read/383134/13/fakta-fakta-serangan-di-mabes-polri-dan-bombunuh-diri-makassar-1617239044.

2 Musdah Mulia, "Perempuan Dalam Gerakan Terorisme Di Indonesia," Al-Wardah: Jurnal Kajian Perempuan, Gender Dan Agama 12, no. 1 (2019): 80-95, https://doi.org/http://dx.doi.org/10.46339/alwardah.v12i1.136.

3 Irwan Nugroho, “Intermeso Dari Novi 'Bom Panci' Hingga Aini," April 4, 2021, https://news.detik.com/x/detail/intermeso/20210404/Dari-Novi-Bom-Panci-Hingga-Aini/.

${ }^{4}$ Febyorita Amelia, Pujo Widodo, And Arief Budiarto, "Motivasi Wanita Sebagai Pelaku Aksi Terorisme Di Indonesia," Peperangan Asimetrik 6, no. 1 (2020). 
dan pendukung ideologi namun kini sudah berani tampil ke ranah publik sebagai pemeran utama mulai dari penyedia senjata, perakit bom bahkan menjadi pelaku bom bunuh diri. ${ }^{5}$

Jumlah memang jumlah lelaki yang terlibat dalam kejahatan terorisme masih mendominasi. Akan tetapi data terbaru menunjukkan adanya kenaikan jumlah perempuan yang ditangkap terkait kasus terorisme pada 2011-2015 yang hanya empat orang menjadi 32 orang dalam kurun wantu 2016-2020.6 Data ini tentunya tidak bisa dianggap remeh, mengingat perempuan adalah sosok yang menghabiskan jauh lebih banyak waktu dan perhatian pada anakanak baik yang apalagi jika mereka mengambil peran penuh sebagai ibu rumah tangga. Pola pikir, ideologi, cita-cita dan harapan keliru mereka sangat besar kemungkinannya untuk diajarkan dan diwariskan pada anak-anaknya. Karena itu diperlukan adanya kajian yang mendalam terkait motivasi apa saja yang mempengaruhi para perempuan sehingga nekat menjadi pelaku bom bunuh diri, agar nantinya dapat dicari jalan keluar agar benih-benih terorisme dapat diberantas dengan pendekatan yang komprehensif, adil dan manusiawi.

\section{PEMBAHASAN}

Perempuan dalam Jerat Terorisme

Walaupun masih dianggap sesuatu yang baru, keterlibatan perempuan dalam aksi teror bunuh diri di Indonesia diyakini merupakan dampak krisis global dari aksi-aksi teror level dunia yang banyak melibatkan perempuan, seperti di Syria, Irak, Afghanistan dan Yaman. Jika sebelumnya perempuan adalah korban pertama dan utama dalam berbagai kasus terorisme, kini posisi itu bergeser drastis. Mereka bukan lagi sekedar obyek dan korban melainkan bermetamorfosis menjadi pelaku dan aktor utama gerakan terorisme. Pertanyaan yang kemudian mengemuka adalah mengapa kelompok terorisme menjadikan perempuan sebagai subyek dan pelaku? ${ }^{7}$

Tentu secara sadar dan logika akal sehat, tidak ada perempuan yang akan memilih menjadi pelaku bom bunuh diri, apapun alasannya. Namun faktanya, mereka sudah terikat dalam jerat lingkar terorisme tanpa tanpa kekuatan untuk bisa lepas. Entah karena ikatan dengan pelaku teroris secara pernikahan, kerabat maupun sebagai simpatisan. Modus baru yang menjadikan mereka sebagai pelaku, hakikatnya mereka adalah korban. Korban dari

${ }^{5}$ Aditya Budiman, “LP3ES Catat Peran Perempuan Dalam Jaringan Terorisme Meningkat," April 2, 2021, https://nasional.tempo.co/read/1448618/lp3es-catat-peran-perempuan-dalam-jaringanterorisme-meningkat/full\&view $=$ ok.

${ }^{6}$ Aria W Yudisthira, "Perempuan Dan Milenial Dalam Aksi Teror Di Indonesia," April 11, 2021, https://katadata.co.id/ariayudhistira/analisisdata/607049e153f0d/perempuan-dan-milenial-dalamaksi-teror-di-indonesia.

7 Mulia, "Perempuan Dalam Gerakan Terorisme Di Indonesia." 
ketidaktahuan, korban dari ketidakberdayaan yang kemudian dimanfaatkan oleh pihak-pihak yang memiliki rencana keji dan sistemik untuk aksi terorisme. ${ }^{8}$

Keamanan adalah sisi lain yang dimanfaatkan oleh para pelaku teror perempuan. Sebab biasanya perempuan dan anak-anak tidak akan menjalani pemeriksaan di berbagai pintu masuk secara ketat oleh petugas, sebab dianggap tidak mungkin akan membahayakan, sebagaimana yang terjadi pada pelaku teror Mabes Polri, yang bisa melenggang masuk, yang diduga dari sistem keamanan ataupun faktor kelalaian petugas jaga. ${ }^{9}$ Anak-anak juga dijadikan tameng untuk mengelabui petugas agar pelaku teror bom bunuh diri dapat leluasa menuju TKP tanpa adanya kecurigaan, sebab secara nalar akan sangat tidak mungkin anak-anak di bawah umur akan melakukan kejahatan terlebih lagi aksi terorisme. Namun, lagi-lagi sangkaan ini terbantah dengan adanya dua kejadian bom bunuh diri di Surabaya, di mana suami yang juga mengajak istri dan anknya untuk melakukan serangan keji. ${ }^{10}$

Peran Perempuan dalam Aksi Terorisme

Peran perempuan dalam aksi terorisme terbagai dalam tiga bentuk yang berbeda menurut Debbie Affianty sebagaimana yang dikutip oleh Leebarty Taskarina ${ }^{11}$ yaitu:

Pertama, pengikut dan pendamping setia. Dalam tahap ini peran perempuan masih sebatas domestifikasi perempuan dalam arti mereka bukanlah aktor utama, melainkan sebagai istri, pengikut setia, dan ibu dari calon-calon teroris.

Kedua, ahli propaganda dan agen perekrutan. Perempuan-perempuan ini belum masuk dalam tahap pertempuran, tetapi mereka berperan sebagai ahli propaganda, pendakwah sekaligus perekrut. Narasinya diawali dari sikap anti pemerintah, yang dihubungkan dengan ketidakadilan penegakan hukum, dan dibumbui narasi agama. ${ }^{12}$

Ketiga, fighter/bomber. Para perempuan ini mengambil peran utama sebagai kombatan, penyedia senjata, perakit bom, bahkan menjadi pelaku lapangan bom bunuh diri. Peran inilah yang dibahas mendalam dalam penelitian ini.

Penyalahgunaan Perintah Jihad Dalam Aksi Terorisme

Kajian terkait jihad dan terorisme dudah dibahas massif sejak adanya tragedy 11 September 2001. Beberapa berpendapat jihad dan terorisme saling berkaitan, padahal hakikatnya keduanya berbeda jauh. Jihad dapat diartikan sebagai sebuah upaya untuk memperbaiki

${ }^{8}$ Leebarty Taskarina, Perempuan Dan Terorisme: Kisah Perempuan Dalam Kejahatan Terorisme (Jakarta: Elex Media Komputindo, 2018).

9 Isnaya Helmi, "Pelaku Teror Lolos Pemeriksaan, Mabes Polri Audit Sistem Keamanan," 2021, https:// www.kompas.tv/article/160375/pelaku-teror-lolos-pemeriksaan-mabes-polri-audit-sistemkeamanan.

${ }^{10}$ Nugroho, "Intermeso Dari Novi ‘Bom Panci' Hingga Aini."

11 Taskarina, Perempuan Dan Terorisme: Kisah Perempuan Dalam Kejahatan Terorisme.

12 Yudisthira, "Perempuan Dan Milenial Dalam Aksi Teror Di Indonesia." 
keimana dan kesejahteraan manusia baik pribadi maupun kelompok dengan prinsip dan aturan yang tertata dan jelas. Sedangkan terorisme cenderung revolusioner, destruktif, menyebabkan ketakutan, kecemasan, dan tidak punya prinsip yang jelas. ${ }^{13}$

Komisi Fatwa Majelis Ulama Indonesia juga sudah mengeluarkan pernyataan bahwa terorisme berbeda dengan jihad. Terorisme adalah tindakan kejahatan terhadap kemanusiaan dan peradaban yang menimbulkan ancaman serius terhadap kedaulatan negara, bahaya terhadap keamanan, perdamaian dunia serta merugikan kesejahteraan masyarakat. Terorisme adalah salah satu bentuk kejahatan yang diorganisasi dengan baik (well organized), bersifat transnasional dan digolongkan sebagai kejahatan luar biasa (extra-ordinary crime) yang tidak membeda-bedakan sasaran (indiskrimatif). Jihad mengandung dua pengertian : a. Segala usaha dan upaya sekuat tenaga serta kesediaan untuk menanggung kesulitan di dalam memerangi dan menahan agresi musuh dalam segala bentuknya. Jihad dalam pengertian ini juga disebut al-qital atau al-harb. b. Segala upaya yang sungguh-sungguh dan berkelanjutan untuk menjaga dan meninggikan agama Allah (li i'laai kalimatillah).14

Pemahaman yang keliru tentang teks perintah agama dapat menimbulkan bencana bagi banyak pihak, tidak terkecuali tentang pemahaman akan perintah berjihad. Perempuan Indonesia yang terlibat dalam gerakan terorisme adalah awalnya mereka terpapar ideologi Islam radikal, di antaranya keyakinan bahwa wajib hukumnya bagi seorang muslim membunuh orang kafir (non-Muslim); meyakini kewajiban menegakkan negara Islam dan khilafah Islamiyah dengan melakukan jihad menumpas ketidakadilan, walau dengan cara membunuh. Mereka juga terjejali dengan narasi ketertindasan sehingga sangat meyakini bahwa umat Islam kini dalam kondisi tertindas karena itu harus diselamatkan dengan jihad. Jihad dalam makna membunuh semua musuh Islam yang mereka istilahkan dengan tagut. Mereka juga didoktrin dengan pemahaman bahwa perempuan harus ikut berjihad membela Islam. ${ }^{15}$

Manisnya Iming-iming Surga

Iming-iming masuk surga adalah propaganda yang paling banyak diberikan jaringan terorisme untuk meyakinkan calom bomber-nya. Semua orang yang percaya agama, pasti meyakini adanya surga, suatu tempat yang digambarkan penuh dengan kenikmatan dan keindahan yang tak akan ada akhirnya, siapapun pasti menginginkannya. Tak terkecuali para wanita pelaku terorisme, yang mendapatkan doktrin keliru tentang mudahnya mendapatkan surge dengan menjadi pelaku bom agar bisa mati syahid. Sebagaimana bunyi surat wasiat yang ditemukan dari pelaku teror Mabes Polri, Zakiah Aini. Di sana selain menulis permintaan maaf pada orang tua, larangan berhubungan dengan bank dan pemerintah yang dianggapnya tagut,

${ }^{13}$ Kasjim Salenda, "Analisis Terhadap Praktek Terorisme Atas Nama Jihad," Alqalam 26, no. 1 (April 30, 2009): 75, https:// doi.org/10.32678/alqalam.v26i1.1516.

${ }^{14}$ Fatwa MUI No. 3 Tahun 2004 Tentang Terorisme.

15 udji Asiyah, Ratna Azis Prasetyo, And Sudjak Sudjak, "Jihad Perempuan Dan Terorisme," Jurnal Sosiologi Agama 14, no. 1 (June 1, 2020): 199, https:/ / doi.org/10.14421/jsa.2020.141-08.

IJouGS: Indonesian Journal of Gender Studies | Volume 2 Nomor 2 
juga berisi keyakinannya bahwa tindakan bunuh dirinya adalah sebuah jalan menuju mati syahid yang dapat menjadi syafaat dan sarana berkumpul di surga. ${ }^{16}$

Bahkan ketika belum menjadi calon pelaku bom bunuh diri, para perempuan yang masih meletakkan dirinya sebagai pihak pendukung, isu masuk surga sudah menjejali otak para perempuan yang terpapar paham radikalisme, sebagaimana yang dituturkan Lies Marcoes, mengutip pernyataan salah satu istri pelaku bom bunuh diri:

"Saya yang menguatkan suami untuk berjihad dengan ikut ISIS di Suriah. Saya bilang 'jangan takut soal Umi dan anak-anak, rezeki Allah yang atur'. Saya bilang ke suami 'Izinkan Umi dan anak-anak mencium bau surga melalui Abi, semoga Abi selamat. Tapi kalau tidak, saya ikhlas, saya bersyukur karena dengan suami menjadi syahid, saya dan anak-anak akan terbawa ke surga". ${ }^{17}$

Pernikahan sebagai Pintu Masuk

Fenomena pelibatan istri dalam aksi terorisme sempat jadi isu hangat media kita. Bahkan beberapa sengaja menjadikannya propaganda dan jalan memuluskan aksi teror mereka. Sebut saja kasus Dian Yulia Novi, yang mengalami indoktrinasi jihad melalui media sosial oleh Nur Solihin yang pada akhirnya menjadi suaminya. Dalam salah satu wawancara Nur Solihin yang merupakan anak buah Bahrun Naim, mengaku, bahwa motif menikahi Dian adalah menjadikannya pelaku mati syahid dengan jalan apapun. ${ }^{18}$

Ada sejumlah nama selain Dian yang berperan sebagai pengantin atau pelaku bom bunuh diri, sejumlah nama dapat disebutkan, seperti Munfiatun (2006), isteri Noordin M. Top berperan sebagai agen rahasia yang menyembunyikan keberadaan para teroris. Siti Rahmah (2008), isteri kedua Noordin M. Top berperan sebagai perekrut dan penyedia logistik. Putri Munawaroh, isteri Adib Susilo berperan penting sebagai agen radikal.Tugasnya merekrut perempuan muda untuk menjadi pelaku bom bunuh diri. Sedangkan Noor Azmi Tibyani, isteri Cahya Fitriyanta memiliki peran khusus sebagai pencari dana untuk membiayai pelatihan militer Poso tahun 2008 dengan menggunakan rekeningnya. Ummu Delima (2014), isteri Santoso berperan penting mendukung suami dalam gerakan terorisme Poso. Lalu, Ika Puspita Sari (2016) di Purworejo berperan sebagai subyek, pelaku bom bunuh diri. ${ }^{19}$

Sebagian mereka direkrut melalui pernikahan, suami sendiri yang melakukan upaya terencana menanamkan ideologi radikal dengan "cuci otak". Artinya, mereka sengaja dinikahi untuk selanjutnya didoktrin dengan ideologi radikal. Pernikahan mereka sebagian berlangsung secara normal, namun tidak sedikit menikah dalam penjara. Sebagian lagi dinikahi belakangan

16 Abdur Rahim, "Begini Isi Surat Wasiat Zakiah Aini Kepada Keluarga Sebelum Lakukan Aksi

Teror Di Mabes," 2021, https://www.kompas.tv/article/160329/begini-isi-surat-wasiat-zakiah-ainikepada-keluarga-sebelum-lakukan-aksi-teror-di-mabes.

17 Asiyah, Prasetyo, And Sudjak, "Jihad Perempuan Dan Terorisme."

18Said Aqil "Piiroj, "Perempuan Dan Terorisme," 2017, https://nasional.kompas.com/read/2017/01/06/12565011/NaN?page=all.

${ }^{19}$ Mulia, "Perempuan Dalam Gerakan Terorisme Di Indonesia." 
setelah mereka menerima doktrin radikal tersebut. Tidak sedikit dari mereka mendapatkan indoktrinasi yang sangat masif dari teman dekat suami atau dari sesama perempuan yang telah terlebih dahulu aktif dalam jaringan tersebut. ${ }^{20}$

Perasaan Terdiskriminasi

Perempuan buruh migran seringkali mengidap kekecewaan dan frustrasi yangsangat dalam akibat perlakuan diskriminatif dan kekerasan fisik yang mereka alami ketika bekerja. Umumnya mereka mengalami berbagai trauma psikologis selama bekerja di luar negeri. Patologi psikis tersebut membuat sebagian mereka mudah menerima pengaruh apa pun yang dianggap dapat menolong mereka keluar dari situasi mencekam tersebut. Sebagian mereka sangat membutuhkan mekanisme pertahanan diri (self defence mechanism) untuk bertahan dari berbagai tekanan sosial. Aksi-aksi terorisme mebuat mereka menemukan kebermaknaan hidup. ${ }^{21}$

Kerja yang merupakan salah satu pengukur martabat manusia membuatnya tergeser secara sosial dari masyarakat Ketika kalah bersaing dengan kemajuan modern banyak manusia terdepak dari pekerjaan.. Mereka yang terasing pun keluar mencari perlindungan dari komunitas primordial semisal agama. Mengapa agama? Karena agama menawarkan penghiburan dan ketetapan hati. Namun, karena tanpa kontrol dan ketundukan buta, manusia yang kalah dari peradaban tersebut kehilangan sikap kritis dan rasionalitasnya. Tidak heran jika kemudian mereka mudah diarahkan berontak kepada peradaban modern yang diklaim sebagai asal muasal segala kejahatan modern. Sejumlah penelitian mengungkapkan,para perempuan tersebut mengalami kekecewaan yang amat dalam, putus asa, mengalami gangguan jiwa, ditekan oleh laki-laki atas nama agama, frustrasi dengan kondisi ketidaksetaraan dan ketidakadilan gender yang ada, ketimpangan sosial di lingkungan mereka dan lain sebagainya. 22

\section{Rasa Frustasi dan Jalan Pintas Menuju Pertobatan}

Nasir Abas, mantan Ketua Jamaah Islamiah (JI) Wilayah Timur, yang saat ini menjadi pengamat terorisme mengungkapkan, orang yang frustrasi dengan masalah hidupnya di dunia akan lebih mudah dipengaruhi paham radikal. Jaringan teroris akan dengan mudah merekrut orang-orang yang terlihat frustrasi dan depresi, serta anak dari keluarga broken home. Orangorang itulah yang nantinya ditargetkan menjadi eksekutor atau pelaku bom bunuh diri. Mereka biasanya akan terus didoktrin dengan kalimat-kalimat yang mensugesti jika hidup sudah sangat tidak menyenangkan, lebih baik berkumpul dengan bapak ibunya di surga dengan jalan mati syahid sebagai pelaku bom bunuh diri. ${ }^{23}$

Selain mereka yang meras frustasi dengan kehidupan, orang yang merasa bahwa dirinya memiliki banyak dosa pun akan mudah untuk direkrut menjadi pelaku bom bunuh diri.

20 Mulia.

${ }^{21}$ Mulia.

22 Mulia.

${ }^{23}$ Rifa Yusya Adilah, "Orang Yang Frustrasi Dan Merasa Berdosa Lebih Mudah Direkrut Jadi Teroris," 2021, https://www.merdeka.com/peristiwa/orang-yang-frustrasi-dan-merasa-berdosa-lebihmudah-direkrut-jadi-teroris.html.

IJouGS: Indonesian Journal of Gender Studies | Volume 2 Nomor 2 
Pertobatan, adalah kondisi yang paling sering ditemukan menjadi faktor pendorong seseorang terpapar oleh ideologi ekstrem. Seseorang yang sedang bergairah mencari pengetahuan agama, lalu dibuat merasa bersalah oleh dosa-dosa masa lalunya. ${ }^{24}$ Target terus diinternalisasi dengan perasaan ketakutan pada kondisinya yang paling rentan. Hingga, untuk menebus dosa itu, target dipicu dengan doktrin jihad "instan". Rasa bersalah yang mendalam akibat menganggap diri sudah melakukan banyak dosa dimanfaatkan oleh para penyebar paham radikalisme dengan alibi dosa pelaku sudah terlalu banyak, jika ingin tobat dengan mudah, mati syahid adalah jalan pintasnya.

\section{Balas Dendam Karena Menjadi Korban Kekerasan Seksual}

Jumlah perempuan yang mengalami kekerasan seksual yang muncul ke permukaan, baik karena pemberitaan media maupun data resmi yang dirilis lembaga terkait tentu kita semua mengerti, itu hanya bagian yang kecil dari situasi yang sebenarnya. Perempuan selalu menjadi korban pertam dan utama dari kasus-kasus kekerasan seksual, di saat kejadian itu berlangsung sampai pasca tragedi. Hampir selalu perempuan yang mendapat stigma buruk seperti perempuan genit, tidak bisa menjaga kehormatan, mudah dirayu dan sebagainya. Bahkan tak jarang cibiran itu justru datang dari sesame perempuan sendiri. Setiap luka fisik dan psikis itu, bagi sebagian perempuan bisa berakumulasi menjadi dendam. ${ }^{25}$

Perempuan dapat menerima kekerasan seksual dari siapa saja, entah itu pacar, mantan pacar, suami, mantan suami atau bahkan orang-orang terdekat dalam keluarga. Rasa takut, marah, tidak bisa melawan, merasa tak berdaya pada titik tertentu berakumulasi menjadi dendam yang mendorongnya melampiaskan kemarahan pada pihak-pihak yang bersalah atau bahkan yang dianggapnya tidak peduli dengan penderitaanya. Milda Istiqomah, peneliti Hukum dan HAM Lembaga Penelitian, Pendidikan dan Penerangan Ekonomi dan Sosial (LP3ES) mencatat peran perempuan dalam terorisme meningkat. Salah satu faktor pemicunya adalah tragedi pribadi yakni para perempuan yang menjadi korban pemerkosaan atau pelecehan seksual lainnya, memunculkan perasaan dendam dan melakukan aksi teror adalah cara mereka balas dendam. ${ }^{26}$

\section{PENUTUP}

Kodrat perempuan adalah kelembutan. Jika mereka bisa direkrut menjadi teroris makan seharusnya mereka juauh lebih mudah dijadikan agen perdamaian. Sebab secara kodrati perempuan diciptakan dengan sebuah rahim untuk merawat keberlangsungan kehidupan manusia. Perempuan memiliki naluri dan jiwa keibuan yang memungkinkannya lebih mudah untuk menjalani tugas-tugas menjaga keberlangsungan hidup, mereda konflik dan memelihara

24 Kalis Mardiasih, “Mengapa Perempuan Bisa Terlibat Dalam Aksi Terorisme?," 2021, https://mojok.co/kal/esai/kolom/mengapa-perempuan-bisa-terlibat-dalam-aksi-terorisme/.

25 Yuliati Hotifah, "Dinamika Psikologis Perempuan Korban Kekerasan Dalam Rumah Tangga," Personifikasi 2, no. 1 (2011): 62-75, https:/ / doi.org/DOI: https://doi.org/10.21107/personifikasi.v2i1.704.

${ }^{26}$ Budiman, "LP3ES Catat Peran Perempuan Dalam Jaringan Terorisme Meningkat." 
perdamaian. Untuk itu, diperlukan strategi yang lebih manusiawi, komprehensif dan pendekatan tanpa kekerasan kepada mereka yang terlibat gerakan terorisme.

Perempuan yang berperan sebagai pelaku bom bunuh diri, sejatinya mereka adalah korban. Korban dari ideologi suami atau keluarga, korban indoktrinasi yang tidak berpihak pada kemanusiaan, korban dari beragam perlakuan negatif yang tidak tertangani dengan baik. Penanganan aksi terorisme adalah tanggung jawab kita bersama, bukan hanya tugas negara dan politisi. Semua elemen masyarakat seharusnya mengambil peran, khususnya pemuka agama dan organisasi keislaman, agar lebih giat mempromosi dan menarasikan wajah Islam yang humanis, toleran, adil, setara dan berkeadilan. Memberantas terorisme juga bukan hanya tanggung jawab polisi dan militer. Sebab, pendekatan keamanan dengan kekuatan militeristik semata hanya akan membuat kelompok tersebut mati suri. Tetapi di balik itu, mereka masih aktif beroperasi, menata ulang strategi dan sel-sel rahasia mereka yang suatu waktu menunggu momentum yang tepat untuk menciptakan ledakan maut yang lebih dahsyat.

\section{DAFTAR RUJUKAN}

Adilah, Rifa Yusya. “Orang Yang Frustrasi Dan Merasa Berdosa Lebih Mudah Direkrut Jadi Teroris," 2021. https://www.merdeka.com/peristiwa/orang-yang-frustrasi-dan-merasaberdosa-lebih-mudah-direkrut-jadi-teroris.html.

Amelia, Febyorita, Pujo Widodo, and Arief Budiarto. "Motivasi Wanita Sebagai Pelaku Aksi Terorisme Di Indonesia." Peperangan Asimetrik 6, no. 1 (2020).

Asiyah, Udji, Ratna Azis Prasetyo, and Sudjak Sudjak. “Jihad Perempuan Dan Terorisme." Jurnal Sosiologi Agama 14, no. 1 (June 1, 2020): 199. https:/ / doi.org/10.14421/jsa.2020.141-08.

Budiman, Aditya. "LP3ES Catat Peran Perempuan Dalam Jaringan Terorisme Meningkat," April 2, 2021. https://nasional.tempo.co/read/1448618/lp3es-catat-peran-perempuan-dalamjaringan-terorisme-meningkat/full\&view $=$ ok.

Fatwa MUI No. 3 Tahun 2004 Tentang Terorisme (2004).

Helmi, Isnaya. "Pelaku Teror Lolos Pemeriksaan, Mabes Polri Audit Sistem Keamanan," 2021. https://www.kompas.tv/article/160375/pelaku-teror-lolos-pemeriksaan-mabes-polriaudit-sistem-keamanan.

Hotifah, Yuliati. “Dinamika Psikologis Perempuan Korban Kekerasan Dalam Rumah Tangga." Personifikasi 2, no. 1 (2011): 62-75. https://doi.org/DOI: https://doi.org/10.21107/personifikasi.v2i1.704.

Mardiasih, Kalis. “Mengapa Perempuan Bisa Terlibat Dalam Aksi Terorisme?," 2021. https://mojok.co/kal/esai/kolom/mengapa-perempuan-bisa-terlibat-dalam-aksiterorisme/. 
Mulia, Musdah. "Perempuan Dalam Gerakan Terorisme Di Indonesia." Al-Wardah: Jurnal Kajian Perempuan, Gender Dan Agama 12, no. 1 (2019): 80-95. https:/ / doi.org/http:/ /dx.doi.org/10.46339/al-wardah.v12i1.136.

Nugroho, Irwan. “Intermeso Dari Novi 'Bom Panci' Hingga Aini,” April 4, 2021. https://news.detik.com/x/detail/intermeso/20210404/Dari-Novi-Bom-Panci-HinggaAini/.

Rahim, Abdur. "Begini Isi Surat Wasiat Zakiah Aini Kepada Keluarga Sebelum Lakukan Aksi Teror Di Mabes," 2021. https://www.kompas.tv/article/160329/begini-isi-surat-wasiatzakiah-aini-kepada-keluarga-sebelum-lakukan-aksi-teror-di-mabes.

Rizky, Fahreza. "Fakta-Fakta Serangan Di Mabes Polri Dan Bom Bunuh Diri Makassar," April 1, 2021. https://nasional.sindonews.com/read/383134/13/fakta-fakta-serangan-di-mabespolri-dan-bom-bunuh-diri-makassar-1617239044.

Salenda, Kasjim. “Analisis Terhadap Praktek Terorisme Atas Nama Jihad.” Alqalam 26, No. 1 (April 30, 2009): 75. https:// doi.org/10.32678/alqalam.v26i1.1516.

Siroj, Said Aqil. "Perempuan Dan Terorisme," 2017. https://nasional.kompas.com/read/2017/01/06/12565011/NaN?page=all.

Taskarina, Leebarty. Perempuan Dan Terorisme: Kisah Perempuan Dalam Kejahatan Terorisme. Jakarta: Elex Media Komputindo, 2018.

Yudisthira, Aria W. "Perempuan Dan Milenial Dalam Aksi Teror Di Indonesia," April 11, 2021. https:/ / katadata.co.id/ariayudhistira/analisisdata/607049e153f0d/perempuan-danmilenial-dalam-aksi-teror-di-indonesia. 